\title{
A DESMATERIALIZAÇÃO COMO ESTRATÉGIA DE ECODESIGN: OBSERVAÇÃO DE UM CENTRO EDUCACIONAL
}

THEDEMATERIALIZATIONASECODESIGNSTRATEGY:OBSERVATION OFANEDUCATIONAL CENTER

Tassiane Bilik, Pós-graduanda (UTFPR)

Adriano Heemann, Dr. (UFPR)

Palavras Chave

Ecodesign; Editorial; Desmaterialização

\section{Key Words}

Ecodesign; Editorial; Desmaterialization

\section{RESUMO}

O design editorial está fundamentado em uma quantidade significativa de mídia impressa. Esse material tem vida útil cada vez menor, sobretudo as folhas de provas didáticas utilizadas por centros educacionais. Diante desse contexto, o presente artigo discute possíveis benefícios da desmaterialização das provas tradicionais confeccionadas em papel e substituição por mídias eletrônicas contemporâneas. O estudo é conduzido com base em uma revisão bibliográfica e uma observação empírica dessa problemática no contexto de um centro educacional no estado do Paraná. O estudo conclui que a estratégia de desmaterialização pode resultar na economia anual de aproximadamente 58,9 toneladas de papel sulfite.

\section{ABSTRACT}

The editorial design is based on a significant amount of print media. This material has ever smaller life, especially the paper sheets of didactic tests used by educational centers. In this context, this article discusses possible benefits of dematerialization of the traditional tests made of paper and replaced by contemporary electronic media. The study is conducted based on a literature review and an empirical observation of this problem in the context of an educational center in the state of Paraná. The study concludes that the dematerialization strategy could result in annual savings of approximately 58.9 tons of paper. 


\section{INTRODUÇÃO}

Segundo o IDEC (2004, p. 33-35), para se produzir 1 tonelada de papel são necessárias até 3 toneladas de madeira (10 a 20 árvores), aproximadamente 10 mil litros de água (mais do que qualquer outra atividade industrial) e 5 mil $\mathrm{kW} / \mathrm{hora}$ de energia, (o quinto lugar na lista das atividades industriais que mais consomem energia). Além desses fatores, o uso de produtos químicos potencialmente tóxicos para a separação e branqueamento da celulose também representa um risco ambiental. De acordo com o IDEC (2004), o contexto do consumo crescente do papel sem posterior reciclagem constitui uma das atividades humanas mais nocivas ao meio ambiente em escala global.

A utilização estrita de madeira de reflorestamento, a utilização racional da água e energia, a aplicação reduzida do uso de cloro nos processos de fabricação e a melhoria da tecnologia de reciclagem são medidas que já vem sendo tomadas por esse setor industrial e que em muito contribuem para a minimização dos efeitos danosos do ciclo do papel. Contudo, essas são medidas que não significam necessariamente a adoção de uma estratégia educacional orientada à sustentabilidade. Diante desse contexto, o presente artigo se baseia em bases teóricas sobre a estratégia de desmaterialização e discute sua pertinência ao design editorial no contexto de um centro educacional.

\section{DESENVOLVIMENTO}

Em termos metodológicos, o estudo aqui relatado é oriundo de uma revisão bibliográfica narrativa, seguida da observação da prática de um centro educacional paranaense que concebe e produz material didático orientado ao preparo de alunos para o ingresso no ensino superior. A revisão bibliográfica é delimitada às principais publicações nacionais sobre Ecodesign. Contudo, não há a intenção de exaurir o conhecimento teórico sobre o tema enfocado, tampouco de modificar a realidade do fenômeno prático observado.

O estudo tem como problema o seguinte questionamento: como a estratégia de desmaterialização pode ser pertinente à prática de um centro educacional? A partir deste problema, a investigação assume caráter qualitativo e adota como objetivo geral sumarizar os principais conceitos teóricos disponíveis na literatura consultada e, com base nisso, argumentar sobre a pertinência de implementação futura de uma estratégia de "desmaterialização" de provas didáticas utilizadas pela empresa observada. O objeto do presente estudo está delimitado papel consumido para confecção das folhas de provas didáticas. Portanto, não considera outros materiais como, por exemplo, tintas, polímeros de encadernação, energia para a produção e transporte das provas.

\subsection{Empresas e ecodesign}

É de conhecimento público que, no século $X X$, as Organizações Não-Governamentais (ONGs) contribuíram significativamente para o aumento da consciência ambiental e reação ao impacto ambiental oriundo do desenvolvimento econômico. Porém, orientar uma sociedade para a sustentabilidade parece não ser um desafio apenas para economistas ou industriais, pois tal orientação implica em aprimoramentos em diversos setores. No âmbito do presente artigo, o enfoque do estudo está delimitado a maneiras mais sustentáveis de se conceber o design editorial.

Dias $(2006$, p. 126) argumenta que entender de gestão ambiental pode ser uma vantagem não só para o meio ambiente, mas também para as empresas, uma vez que pode aumentar a competitividade das mesmas. Já, para Kazazian (2005), pode haver vantagem concorrencial a empresas que atrelam seu nome a aprimoramentos diversos, como o de respeitar o meio ambiente. Contudo, "outras motivações podem existir, principalmente a meIhora da qualidade dos produtos, a redução dos custos e o estímulo interno pela inovação" (KAZAZIAN, 2005, p. 36). Manzini $(2008$, p. 23) sugere que "para ser sustentável, um sistema de produção, uso e consumo deve ir ao encontro das demandas da sociedade por produtos e serviços sem perturbar os ciclos naturais e sem empobrecer o capital natural". Nesse mesmo sentido, Savitz e Weber (2006, p. 2) apontam que "uma empresa sustentável é aquela que gera lucro para os acionistas e simultaneamente protege o meio ambiente e melhora a vida das pessoas com quem interage". Para os autores, a ecoeficiência é o componente básico para a sustentabilidade e significa a redução dos componentes utilizados para a produção dos bens e serviços. Isso geralmente aumenta de forma direta os lucros da empresa e reduz o impacto ambiental. DIAS (2006, p. 135) acrescenta que a ecoefiência consiste em se produzir mais com menos, reduzir a geração de resíduos e a poluição no meio ambiente, além de possíveis responsabilidades por danos a terceiros.

Atualmente, a adoção de uma postura de design orientada a sustentabilidade parece ser um dos princípios fundamentais da gestão empresarial eficiente, embora não possa ser considerada garantia de sucesso financeiro de um projeto. Ademais, sua adoção exige comprometimento, assim como recursos e cuidados extras diante de alterações de estratégia, o que por sua vez pode acarretar custos e riscos adicionais (SAVITZ e WEBER, 2006, p. 234). Os autores mencionam um lado mais abstrato que converge para as oportunidades e riscos de mais difícil quantificação: a reputação da empresa, a satisfação dos empregados, a boa vontade dos clientes e o valor a ser considerado líder setorial (SAVITZ e WEBER, 2006, p. 39). 


\subsection{O design orientado à sustentabilidade}

Segundo Krucken, um dos principais desafios do design contemporâneo consiste em "suportar o desenvolvimento de soluções para questões de alta complexidade, que exigem uma visão abrangente do projeto, envolvendo produtos, serviços e comunicação de forma conjunta e sustentável" (KRUCKEN, 2009, p. 44). Daí emerge o papel-chave do designer, uma vez que ele é um dos responsáveis por cogitar e selecionar materiais, processos produtivos e de definir o modo de operação de produtos, serviços e sistemas. Papanek (2007) aponta que as decisões dos designers "podem ter consequências ecológicas de grande alcance e a longo prazo" (PAPANEK, 2007, p. 31).

Para o IDHEA (2009), o conceito de Ecodesign pode ser definido em linhas gerais como

a ferramenta de projeto utilizada para o desenvolvimento de serviços e produtos, cujos processos não resultem em impactos sobre o meio ambiente, com a minimização no consumo de matérias-primas, redução na emissão de poluentes e efluentes e na geração de resíduos (2009).
Segundo MANZINI $(2008$, p. 28) Quando se objetiva a sustentabilidade, uma descontinuidade sistêmica deve acontecer e o centro de interesse deve passar a ser os resultados, focalizando o projeto nas atividades a serem realizadas. Ora, projetar soluções sustentáveis demanda o atendimento de uma série de requisitos (também aqueles tradicionais) que precisam ser harmonizados num todo. Assim, projetar é uma atividade cada vez mais complexa. Os sistemas passam a ser projetados de tal forma que também o consumo de recursos seja reduzido e o valor do que é projetado seja melhorado (MANZINI, 2008, p. 36).

OEcodesign, no contexto exposto por Papanek (1995), é um processo que tem por consequência tornar a economia mais "leve". Ou seja, consiste em reduzir os impactos de um produto e ao mesmo tempo conservar suas qualidades de uso, com o intuito de melhorar a vida dos usuários de hoje e amanhã. Esse mesmo processo é também chamado de "eco-concepção" por Kazazian (2005, p. 36). A gestão da concepção de produtos deve levar em conta não só as características físicas que satisfaçam o consumidor, mas também as variáveis ambientais que poderão alterar o produto em sua forma original (DIAS, 2006, p. 144).

Figura 01 - Ciclo de vida na eco-concepção

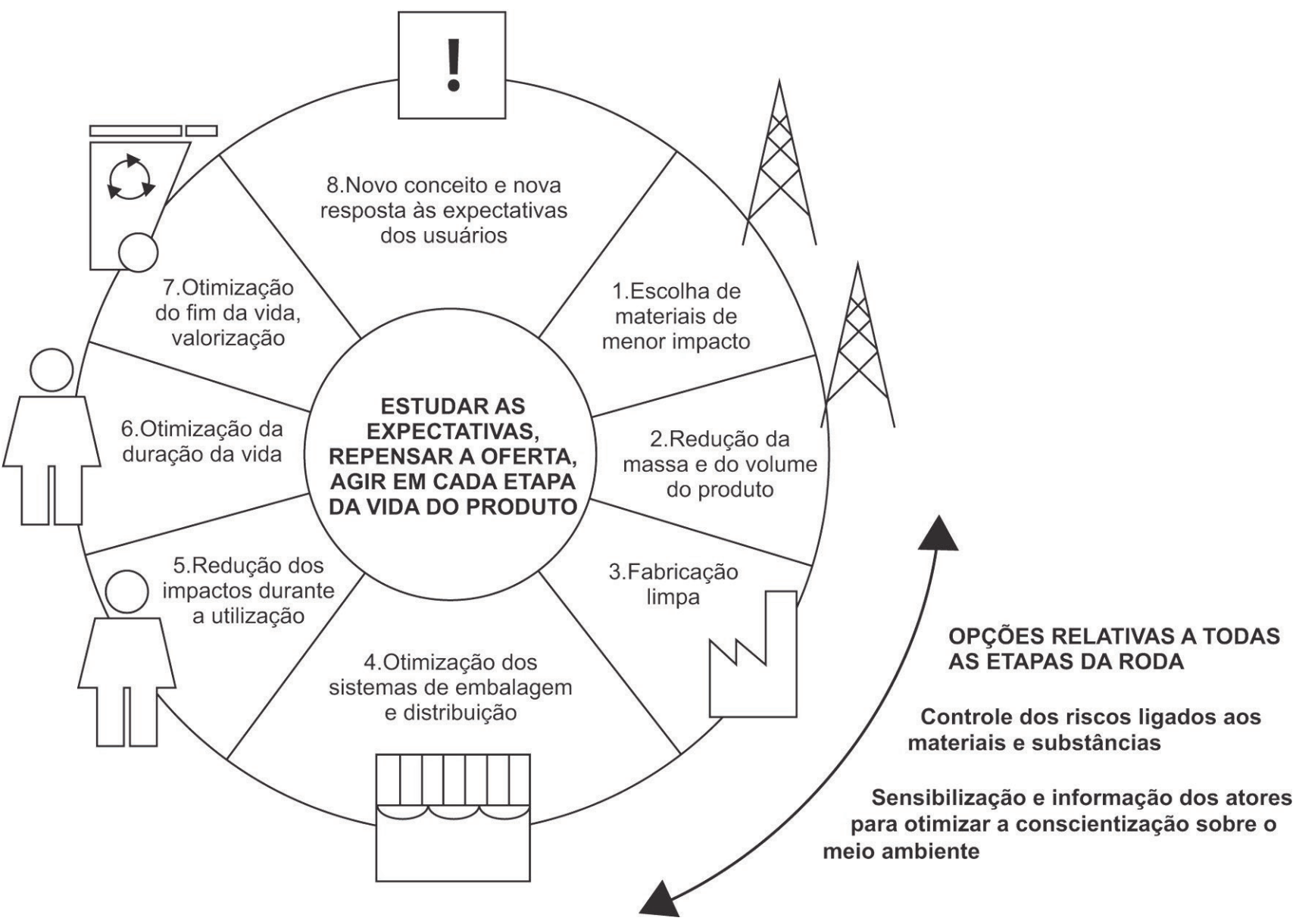

Fonte: Kazazian (2005) 
Kazazian (2005, p. 36) ilustra sua argumentação de que, no processo de eco-concepção, o designer criador articula soluções para todo o ciclo do produto, incluindo os seus impactos ambientais (figura 01). Assim, o Ecodesign emerge como uma maneira de conceber um produto adequado em todo o seu ciclo de vida. Kazazian esclarece que o ciclo de um produto sustentável ideal, passa por etapas importantes como a escolha de materiais de menor impacto, redução na massa e volume, assim como a otimização da vida útil do mesmo, o que melhorará a percepção do valor do produto aos usuários.

Mas o designer antes de tudo deve aprender a desenvolver produtos e serviços também sustentáveis e, a partir daí, promover novas configurações entre diferentes atores buscando soluções inovadoras capazes de agregar interesses sociais, ambientais, tecnológicos e econômicos, o que ainda parece ser um desafio novo e considerado complexo para a cultura e prática do design (VEZZOLI, 2010). O autor apresenta três elementos-chave do design orientado para a sustentabilidade (VEZZOLI, 2010, p. 40):

- Unidade de satisfação como referência, ou seja, design da demanda/satisfação;

- Interação de atores como foco, ou seja, design das relações entre os atores envolvidos;

- Sustentabilidade como objetivo, ou seja, design para sistemas ecoeficientes e socialmente coesos e justos.

O autor ainda apresenta requisitos típicos e algumas diretrizes de projeto para minimizar o impacto ambiental (VEZZOLI, 2010, p. 59):

- Minimizar o uso dos recursos;

- Selecionar recursos e processos de baixo impacto ambiental;

- Otimizar a vida dos produtos;

- Estender a vida dos materiais;

- Facilitar a desmontagem.

A necessidade de operacionalização do Ecodesign não é nova, tampouco isolada. A ela está atrelada uma série de outras demandas por abordagens concretas que operacionalizem os novos modelos de consumo e produção mais sustentáveis no Brasil. A esse respeito, Santos (2015) apresenta o exemplo do Design de Sistemas Produto+Serviço (PSS), definido como resultado de uma estratégia mais ampla de inovação, redirecionando o foco de negócios do design da mera venda de produtos físicos para a venda de PSSs, que são conjuntamente capazes de atender integralmente demandas específicas de clientes. Portanto, uma mudança de abordagem desse tipo parece favorecer a desmaterialização do consumo com possíveis benefícios ambientais, econômicos e sociais para todos os atores sociais como, por exemplo, governo, empresas e consumidores.

A sustentabilidade em projetos pode ser buscada por meio de uma multiplicidade de percursos, esses percursos podem ser subdivididos em três famílias fundamentais (MANZINI e VEZZOLI, 2008, p. 41). Percursos na área da eficiência são alcançados, por exemplo, quando os produtos limpos são recicláveis e operam no âmbito de uma ecologia industrial fechada e caracterizada por tecnociclos. Percursos na área da suficiência são atingidos quando os produtos são biológicos e biodegradáveis, caracterizados no âmbito da ecologia industrial por biociclos. Finalmente, percursos na área da eficácia partem dos atuais produtos e serviços ecoeficientes, isto é, com baixa intensidade de material. Em outras palavras, os percursos que enfocam a eficácia parecem ser caracterizados por uma ecologia industrial fortemente desmaterializada. Isso significa que os processos produtivos implícitos (sejam eles orientados à não-interferência ou à biocompatibilidade) devem tornar-se mais eficientes, mais leves, apresentar produtos finais com conteúdo mais elevado de conhecimento e informações e ainda contribuir para aumentar a inteligência do sistema.

A esse respeito, cabe ainda a observação de Kazazian, sugerindo que a desmaterialização tem por objetivo a redução do input, ou fluxo de matérias, no funcionamento econômico. Tem por objetivo principal descasar o crescimento econômico da exploração de matérias-primas, isto é tornar a primeira menos dependente da segunda (KAZAZIAN, 2005, p. 62). Conforme o autor, as estratégias de desmaterialização utilizam a otimização de seus meios como ferramentas de produção e concepção de produtos, sistemas e serviços que permitem que uma determinada empresa chegue a um resultado superior em comparação a aquele oriundo de uma estratégia clássica. A desmaterialização se torna ainda mais necessária em empresas que já se enquadram na evolução dos critérios de poder atual baseados em valores cada vez mais imateriais e intangíveis como, por exemplo, o domínio de marcas, de conhecimento científico ou tecnológico, as transferências de informação ou as estratégias de organização.

\subsection{Possibilidade de desmaterialização em um centro educacional \\ Em termos conceituais, a desmaterialização em pro- jetos parece ocorrer quando um produto passa a ter sua função e seu valor de uso significativamente ampliados em comparação a produtos similares. No caso do design}


editorial observado em um centro educacional paranaense, a função de testar a capacidade de aquisição e retenção de conhecimento de alunos é atualmente mediada por provas tradicionais, impressos em folhas papel sulfite. De acordo com o que foi levantado durante a investigação (tabela 01), centenas de provas são impressas e reimpressas semanalmente em diferentes séries e frentes de ensino, o que totaliza o consumo de mais de 12 milhões de folhas (ou aproximadamente 58,9 toneladas) de papel sulfite a cada ano.

Cabe aqui considerar a existência de um exemplo de desmaterialização do papel denominado Kindle, desenvolvido pela empresa Amazon. No Kindle, podem ser utilizadas alternativas para o conforto do leitor, como a escolha da tela e-Ink, que emula o aspecto do papel impresso. Outro exemplo de ferramenta que pode dispensar o uso de papel são os tablets. Eles oferecem mobilidade, são menores e mais leves do que um computador comum, dispõem de espaço para amplo armazenamento de informação, como apostilas, livros, revistas, filmes, etc. em uma só mídia. Ambos os equipamentos podem ser considerados plataformas que apresentam a vantagem da interação com o conteúdo a dão suporte. Exemplos são as funções de editar, salvar, fotografar, sublinhar, ou seja, realizar articulações entre conteúdos de interesse. Dispositivos eletrônicos ainda podem oferecer conectividade a intranet e internet.

Entretanto, o advento das mídias digitais em substituição ao papel também pode significar desafios de desenvolvimento. De acordo com Chartier, a empresa multimídia, em termos de rentabilidade, só pode ser eficaz sob três condições: que ela seja implantada no maior número de regiões produtivas no mundo, que ela congregue atividades afins - cada produto sendo, portanto, desde a origem, concebido para a diversificação -, e também que ela tenha uma capacidade de investimento enorme, com os crescentes custos de acesso aos bancos de dados (2009, p. 147).

No caso do material didático do centro educacional observado, o conceito de eco-concepção poderia ser aplicado por meio da inserção de conteúdo digital (desmaterializado) aos alunos e professores, em substituição ao consumo de material didático tradicional em papel (consumido e descartado anualmente). Neste caso, o acesso ao conteúdo didático digital, por sua vez, ocorreria por meio do acesso a mídias eletrônicas contemporâneas como smartphones, tablets, notebooks e computadores que já são de propriedade de alunos e professores. Para usuários que não dispõem de aparelhos desse tipo, o centro educacional poderia empresta-los temporariamente por meio de comodato.

Cumpre observar que, embora o ciclo de vida de produtos eletrônicos também emerja mundialmente como um problema ambiental significativo, a estratégia de desmaterialização aqui argumentada não prevê a produção de novos aparelhos eletrônicos para esta finalidade, mas sim o aproveitamento dos aparelhos que já são utilizados pelos usuários. Um aproveitamento desse tipo aumentaria

Tabela 01: Levantamento do consumo de papel em provas no centro educacional observado (2015)

\begin{tabular}{|c|c|c|c|c|}
\hline Função do Material Didático & Qt de/ano & Nr. páginas & Tiragem & Folhas \\
\hline Fascículo Revisões - Terceirão & 18 & 30 & 5000 & 1350000 \\
\hline Semiextensivo & 6 & 32 & 2000 & 192000 \\
\hline Aprofundamento geral & 26 & 14 & 2000 & 364000 \\
\hline Aprofundamento - Biológicas & 24 & 12 & 3000 & 432000 \\
\hline Aprofundamento - Tecnológicas & 24 & 12 & 1300 & 187200 \\
\hline Aprofundamento - Humanísticas & 24 & 12 & 1500 & 216000 \\
\hline Fascículos & 40 & 10 & 400 & 80000 \\
\hline Provas & 11 & 26 & 2500 & 357500 \\
\hline Simulados & 3 & 60 & 5000 & 450000 \\
\hline Simulados - Semiextensivo & 6 & 60 & 2500 & 450000 \\
\hline Revisão & 1 & 216 & 5000 & 540000 \\
\hline Maratona - ENEM & 1 & 272 & 5000 & 680000 \\
\hline Reforço & 1 & 220 & 5000 & 550000 \\
\hline Maratona - Vestibular & 1 & 448 & 5000 & 1120000 \\
\hline Superextensivo & 1 & 508 & 5000 & 1270000 \\
\hline Discusivas & 1 & 1768 & 5000 & 4420000 \\
\hline $\begin{array}{l}\text { Total } \\
\text { Papel } 75 \mathrm{~g} / \mathrm{m}^{2} \text { se } 4,65 \mathrm{~g} / \text { folha } \mathrm{A} 4\end{array}$ & 188 & 3700 & 55200 & $\begin{array}{c}126658700 \\
58,9 \text { Ton }\end{array}$ \\
\hline
\end{tabular}

Fonte: Autores 
o valor de uso tanto do aparelho quanto da mídia didática (então em formato digital). Além disso, com o uso da mídia digital, o usuário disporia de uma gama significativamente ampliada de possibilidades de provas didáticas, imateriais, interativas e atualizáveis, o que a mídia convencional em papel não é capaz de suportar. Assim, o valor e a função do conteúdo didático seriam ampliados significativamente, com importante redução de desperdício de material.

\subsection{Discussão}

Com base no referencial apresentado anteriormente, é possível argumentar que a desmaterialização pode constituir uma estratégia de Ecodesign pertinente ao centro educacional observado. A difusão de produtos digitais e serviços ecoeficientes apresenta uma notável convergência com o crescimento da economia de serviços e da informação, o que é uma das características das sociedades industrialmente maduras. A desmaterialização da economia na perspectiva da sustentabilidade pode ser vista como uma reorientação ambiental de um grande fenômeno em ação (MANZINI e VEZZOLI, 2008, p. 52-53).

Para aluno e professor, além de disporem de todo material usual das aulas em um único dispositivo com o volume reduzido, a desmaterialização das provas poderia ampliar a gama de funções para esses usuários. Estes poderiam vir a utilizar os dispositivos de formas ainda mais eficientes como, por exemplo, na comunicação entre alunos com professores, exibição de aulas e provas online, vídeos, filmes, exercícios com respostas instantâneas, autoavaliações, orientações online, gráficos do rendimento do aluno, simulados, depoimentos de ex-alunos disponíveis em vídeo, fóruns com dicas pedagógicas, etc.

Para ilustrar ainda mais esta discussão, cabe recorrer a observação de Chartier (2009, p. 137), de que no livro digital, a composição na tela, a transmissão ao leitor, a recepção, a leitura e o armazenamento na memória informática são efetuadas sem que em nenhum momento haja inscrição em papel: isso torna uma realidade na micro-edição e nada nos impede de pensar que um dia se generalize.

O presente estudo também simulou a utilização de tablets não apenas para a realização de provas, mas também para a interação com apostilas e livros, a digitação de redações, o acesso a internet e comunicação entre alunos e professores. Observou-se, sobretudo, que a mídia digital proporciona mobilidade de uma ampla gama de informação, com leveza e baixa intensidade de material. Também os meios de acesso a mídia digital são ampliados, atualmente podendo se dar de modo sincronizado entre tablets, smartphones, notebooks ou computadores pessoais.
Contudo, o "produto" do centro educacional não seria a prova em papel, nem mesmo o aparelho eletrônico (hardware). Corroborando a estratégia da desmaterialização, neste novo arranjo, o produto da empresa passaria a ser o "serviço" que o usuário acessa (software). Assim, não mais seriam consumidas as 12 milhões de folhas (ou aproximadamente 58,9 toneladas) de papel sulfite a cada ano por este centro educacional. Embora o escopo do presente estudo não tenha englobado diferentes tipos de materiais didáticos de auxílio, é possível estimar que estes também poderiam passar a ser dispostos de modo digital, o que reduziria ainda mais o consumo de papel além de outros recursos.

Finalmente, no que concerne ao aproveitamento dos dispositivos eletrônicos já pertencentes aos usuários, cabe resgatar o raciocínio de que, como apresentado por Manzini e Vezzolli,

se um produto tem uma vida útil maior, não vai ser necessário novos materiais para serem transformados em novos produtos, isto é, confeccioná-los, transportá-los, e descartá-los, com toda a respectiva carga de impacto ambiental que o acompanha (2008, p. 150).

\section{CONCLUSÃO}

O presente artigo apresenta a sumarização dos principais conceitos teóricos disponíveis na literatura consultada e, com base nisso, apresenta argumentação sobre a pertinência de implementação futura de uma estratégia de desmaterialização de provas didáticas.

A perspectiva adotada, contudo, não é nova e o estudo aqui relatado tampouco é exaustivo. A estratégia de desmaterialização de provas didáticas, aqui demonstrada como sendo pertinente ao caso enfocado, deve ainda ser objeto de outros estudos que considerem os múltiplos aspectos e requisitos específicos da empresa.

Um plano operacional para tal desmaterialização transcende este estudo delimitado a uma etapa preliminar do assim chamado design estratégico. Contudo, uma vez que aceita a pertinência da conjectura aqui apresentada, a determinação do plano operacional constituiria um objetivo promissor para pesquisas futuras, provavelmente de natureza quantitativas e transdisciplinares, aderentes aos campos do Design, Marketing, Engenharia de Produção, Tecnologia da Informação, Gestão, Pedagogia entre outros.

Como discutido neste artigo, a estratégia da desmaterialização pode culminar em vantagens ambientais e de utilização. Contudo, conclui-se, finalmente, que sua implementação futura em um centro educacional também poderá constituir fator de inovação e de destaque perante as demais empresas do setor. 


\section{AGRADECIMENTO}

Os autores agradecem à Fundação Araucária do Paraná pelo apoio na forma de bolsa de estudos.

\section{REFERÊNCIAS}

IDEC. O lado escuro do papel. Revista do IDEC, São Paulo, v. 1, ed. 77, mai. 2004. Disponível na internet por http em: <http://www.idec.org.br/uploads/revistas_materias/pdfs/2004-04-ed77-servico-ambiente.pdf $>$. Acesso em: 23 dez. 2015.

DIAS, Reinaldo.Gestãoambiental:Responsabilidade social e sustentabilidade. São Paulo: Atlas, 2006.

KAZAZIAN, Thierry. Haverá a idade das coisas leves: design e desenvolvimento sustentável. São Paulo: Editora SENAC, 2005.

MANZINI, Ezio. Design para a inovação social e sustentabilidade: comunidades criativas, organizações colaborativas e novas redes projetuais. Rio de Janeiro: E-papers, 2008.

SAVITZ, Andrew W.; WEBER, Karl. A Empresa sustentável: o verdadeiro sucesso em lucro com responsabilidade social e ambiental. Rio de Janeiro: Elsevier, 2007.

KRUCKEN, Lia. Design e território: valorização de identidades e produtos locais. São Paulo: Studio Nobel, 2009.

PAPANEK, Victor. Arquitetura e design: ecologia e ética. Lisboa: Edições 70, 1995.

Ecodesign. Instituto para o desenvolvimento da Habitação Ecológica (IDHEA). Disponível na internet por http em: <http://www.idhea.com.br/ecodesign.asp>. Acesso: 11 jan. 2016.

VEZZOLI, Carlo. Design de sistemas para sustentabilidade: teoria, métodos e ferramentas para o design sustentável de "sistemas de satisfação". Salvador: EDUFBA, 2010.

SANTOS, Aguinaldo dos. A premência de competências no país para o design de sistemas produto+serviço. Design Brasil, 2015. Disponível na internet por http em: <http://www.designbrasil.org. br/entre-aspas/a-premencia-de-competencias-no-pais-para-o-design-de-sistemas-produtoservico/\#. VoluimSrS01>. Acesso em: 5 jan. 2016.

MANZINI, EZio; VEZZOLI, Carlo. O desenvolvimento de produtos sustentáveis. São Paulo: Editora da Universidade de São Paulo, 2008.

CHARTIER, Roger. A aventura do livro: do leitor ao navegador. São Paulo: UNESP, 2009. 